\title{
5. The national taboo of hydrocarbon culture: changing the Arctic environment
}

In this chapter, I want to examine how the Russian hydrocarbon culture manifests itself in the Arctic. Specifically, I ask what role does the Russian North, a central geopolitical direction of Putin's Russia, play in safeguarding the future of the regime and its chosen economic and political trajectory. Moreover, I use the spatialities of energy, including the pivotal leakage of carbon, to show how the Russian hydrocarbon culture contributes to environmental problems ranging from the local to the global, and in fact functions as a 'geological force' that is transforming the Arctic environment to serve the needs of this very culture. However, in doing so the culture relies on three Arctic paradoxes: local, national and global. The hydrocarbon culture is unable to address these paradoxes, and instead they are implicitly defined as societal taboos. The inability to address these problems is a central obstacle on the path towards a resilient and sustainable Russia.

\section{PATH DEPENDENCY AND NATION-BUILDING IN AN 'EXCEPTIONAL' ARCTIC CONTEXT}

The Arctic arouses many associations and emotions. Discovery, human bravery, exploration and scientific progress are connected to the 'adventure' Arctic. The Cold War, submarine chases, closed military compounds and regional environmental problems, such as the fall-out caused by nuclear tests, are attributes of the 'battlefield' Arctic. Inter-governmental cooperation to build understanding across the North Pole, and the international environmental movements and Northern indigenous people that emphasize the urgency to act regarding global climate change fall into the semantic field of the 'global' Arctic. Over the course of the twentieth century, the political image of the Arctic has undergone a metamorphosis, and it seems like we are witnessing a new turn in Arctic contestation. 
During the last decade, the Arctic cooperation agenda that emphasizes the grassroots level, such as cooperation between inter-governmental institutions, non-governmental organizations and Northern indigenous people, has witnessed a revival of so-called 'hard' issues. There are high hopes that environmental change will open up new resources for extraction and, in the wake of economic ambitions, geopolitics is once again assuming a more pivotal role in defining the Arctic. The global 'Arctic paradox', which describes the situation when the changing climate enables the exploitation of new Northern energy resources and further intensifies climate change (Heininen 2018) seems to be ignored as the world fixes an intense gaze on the Arctic mineral riches (Gritsenko 2018). The global Arctic paradox is in fact an ethical problem, since the greenhouse gases released from hydrocarbon extraction and use have a particularly strong impact in the Arctic. In addition, the uncertainties related to the rapidly melting sea ice and thawing permafrost are being covered up, while the economic prospects of Arctic industrialization are exaggerated (Gritsenko and Tynkkynen 2018; Palosaari and Tynkkynen 2015; see Chapter 6). These global tendencies seem to be particularly true in Russia, where the Arctic is actively being turned from an 'uninhabitable' periphery (see the section on the definition of sustainability below) into a geopolitically central area interwoven with nationbuilding and Great Power political identity construction in a novel way.

A few years ago, Marlene Laruelle (2012) proposed that the three central discourses linked to geopolitical, national identity and state construction in Putin's Russia are Eurasia, Cosmos and the Arctic. For those following Russian politics, Eurasian-ness and the geopolitical fervour linked to it are familiar via the demagogues that have occupied podiums in Russia and beyond after the break-up caused by the Ukrainian war: Russia is a rising Eurasian Empire that is separate from the decadent and thus declining Europe. Cosmos refers to both the Cold War-era space race that draws on deepening Soviet nostalgia among Russians and the importance of spirituality that has grown hand-in-hand with the political power of the Russian Orthodox Church. Finally, Arctic objectives and ideals are also discussed with history, since this discourse is constructed by referring and appealing to achievements of the Soviet state in the High North: the state-building geopolitical discourse of Putin's Russia is thus partly dependent on the selective utilization of history from the tsarist and Soviet eras (for example, Tynkkynen 2016a). This discourse naturally aims at and looks into the future, where achievements in the Arctic will pave the way for the strengthening of national economic power. 
The geopolitical discourse on the Arctic that began in Russia during the last decade is, nevertheless, a consequence of several global, regional and national phenomena and processes. One of the most important drivers is the climate change that is advancing at an accelerated pace in the region. The vision of an ice-free Arctic Ocean as well as the estimates of rich hydrocarbon deposits located on the Russian Arctic continental shelf have been pivotal in pushing economic activity in the region. The expectations that the loss of sea ice will transform the Northeast Passage into a key route linking Europe and Asia, forming an interface between the geopolitical discourses of Eurasia and the Arctic, highlight how the economic and political needs of the governing regime are intertwined (Medvedev 2018). Domestic and foreign policy needs that are partly symbolic and partly compulsive force Putin's Russia to be an increasingly military presence in the Arctic and emphasize its sovereignty in the region, for example, via territorial claims (Baev 2018). In addition, the emphasis on hydrocarbon sector development, chosen both for economic and power-related reasons, is compelling Russia to expand its Arctic activity. However, this is not a choice in the original meaning of the word, but rather a path dependency caused by hydrocarbon culture and its spatial logic: it creates favourable conditions for oil and gas to the detriment of other sectors of the national economy, and also accentuates large-scale, state-led projects with the help of authoritarian rule. This path dependency is not limited to the sphere of Russian economics and politics; in the spirit of building the hydrocarbon culture, it also encompasses the society and culture (Tynkkynen 2016a, 2016b).

For the time being, many Arctic mega-projects have been put 'on hold' due to the relatively low price of oil. The large-scale plans to turn the Russian Arctic into a patchwork of offshore oil rigs and gas pipelines, as envisioned in the Energy Strategy of the Russian Federation in 2009, have not materialized, despite the fact that Russia tried to influence the price of oil by striking a deal with OPEC to cut oil production in late 2016. The two energy complexes envisioned before the oil price drop in 2014 and subsequently carried out - the Prirazlomnaya oil field at the Kara Sea and the Yamal LNG production and transport facilities on the Yamal Peninsula - may prove to be risky investments both for the Russian state and private investors. International companies participating in Arctic energy projects are very scarce at the moment, primarily because of low oil prices but also due to sanctions imposed by Western countries on Russia after it began its aggression in Ukraine (e.g. Aalto 2016). The sanctions specifically target Russia's future hydrocarbon developments in the Arctic. Given the importance of the Arctic for Putin's vision of the Russian future, it cannot be anticipated that the 
large-scale plans to exploit the Arctic, now firmly locked in the drawers of the governing regime, would be scrapped. However, without energy technologies of Western origin - which are now subject to sanctions Russia's Arctic energy conquest is not going to be easy, if it is even possible at all (Aalto 2016). Hence, the importance of Arctic cooperation is underlined in Russian foreign policy discourse, which claims that the Arctic forum is actually an arena of like-minded actors and thus insulated against conflicts elsewhere - in Ukraine, Syria and beyond. At the same time, however, the domestic discourse and rhetoric targeting the Russian people have defined the Arctic as a territory where Russia's interests are at odds with those of others, especially Western actors, whose aim is to plunder Russia's natural riches (Gritsenko and Tynkkynen 2018; see discussion below). Therefore, framing of the Arctic as an 'exceptional' context - one in which all actors emphasize the rule of law and play by the international norms - fits in well with the alternative-less trajectory of a Russian political elite that is compulsively clinging to hydrocarbons.

For some Western and Asian actors, it may be appealing to nurture this exceptionalism in the hope of quick economic returns, even to the point of naivety. Arctic cooperation in the field of energy, environment and culture is a good candidate to become a source for advancement that leads to détente between Russia and the West. This should be nurtured, while still keeping in mind the political and environmental risks that potentially accompany such a choice. At this moment, therefore, it is worth asking explicitly: what objectives are being promoted in the name of 'Arctic exceptionalism'? Does the global community want to foster a Russia that nestles in and around hydrocarbons, strengthening the hydrocarbon culture and dooming it to a deeper resource dependency that further erodes its democratic institutions and maintains a centralized and unpredictable rule? Or is it able to see Russia and its northern expanses as a context where local livelihoods are a central component in a flourishing and sustainable economy, and mitigation of and adaptation to climate change is taken seriously, including a bold investment programme targeting the vast potential in renewable natural resources and energy?

\section{PARADOXES OF AN ARCTIC-CENTRED HYDROCARBON CULTURE RUSSIA}

Russia's great power ambitions coalesce in the Arctic through a combination of traditional sovereignty staking out a 'new' territory, economic rents captured from the region's natural resources and sea routes, and 
strengthening of the global energy superpower image. Despite all this Russian blustering Lebensraum thinking (e.g. Laruelle 2012), the Arctic policy of the future will also be defined by cooperation. However, the present trajectory poses several paradoxical risks to Russia as it reaches towards its Arctic.

The Russian Arctic paradox is of a less profound nature than the ethical problem raised by the global Arctic paradox - climate change melts the ice and further accelerates the exploitation of Arctic hydrocarbons - as this national paradox is linked to the fluctuating global price of oil and potentially changing ideas about Russia as a Great Power. The Russian Arctic paradox is caused by the need for Russia to be visibly present in the Arctic and along the Northern Sea Route in order to enhance its Great Power status, as well as the fact that Russia has, in an economic, political and even cultural sense, become chronically dependent on hydrocarbons (for example, Gustafson 2012; see Chapter 3). These factors push the Russian state to promote and finance non-viable oil projects in the Arctic for the time being, and to do everything in its power to influence the price of oil via its energy diplomacy and foreign policy in the global arena in order to make Arctic oil projects profitable and increase budget revenues. At the grassroots level, in contrast, we see the local Arctic paradox: hydrocarbon-based workers' towns are well maintained and even indigenous communities are 'subsidized', or compensated for the economic losses produced by the industries, but the long-term economic and sociocultural strategies that reach beyond the time frame of hydrocarbon industries are missing (for example, Henry et al. 2016). This local Arctic paradox mirrors the general paradox facing Russian society: how to prosper after oil? Unlike the global Arctic paradox, the local Arctic paradox in the Russian High North is easier to act on, for example, via corporate social responsibility practices that we monitored (Tynkkynen et al. 2018) in the Yamal Peninsula. However, as long as this activity is labelled as 'charity' - as it predominantly is by major actors in the High North: Gazprom, Rosneft and Novatek - we are unable to resolve this paradox on a strategic level. In this respect, internationally agreed supply chain and commodity certificates could play a decisive role (see the concluding chapter). After all, it is us in the EU, Japan and China who are the primary consumers of Russia's energy resources, and it is in our interest to increase responsibilities along the energy supply chain.

By approaching Russia's Arctic paradoxes from different disciplinary traditions, in addition to the above-mentioned spatial approach, we are able to draw a more nuanced picture of the factors and path dependencies behind these paradoxes. First, seen from the perspective of political 
economy, the agenda and decisions concerning industrialization of the Russian Arctic seem legitimate, at least in the short term. Arctic hydrocarbons are pivotal in the quest to maintain high levels of oil and gas production, and the related rents. The resource rents are central to Putin's popularity; along with boosting military capabilities and the domestic security structures, these rents have been utilized for the benefit of Russian citizens in social transfer schemes and via the economic trickle-down effect. The link between energy rents and the regime's popularity seems to be holding for now, despite the fact that during the Putin era that began in 2000, the affluence of the Russian nation - the energy-linked capital - has accumulated in fewer and fewer hands than ever before, while a significant share of the population persistently remains below the poverty line (Shorrocks et al. 2016). Control over these rents is also vital to the self-preservation of the governing regime, as the political and economic elite - first and foremost the oligarchy - is kept loyal through 'carrots' and 'sticks' derived from energy flows and rents. Thus, the entanglement of economic interests and those of the political elites and the resulting absolute priority of the natural resource sector is a key reason why Putin's Russia cannot avoid leapfrogging to the Arctic 'big fish' with its major virgin and greenfield deposits of oil and gas (for example, V.-P. Tynkkynen 2010; Tynkkynen 2014; also see Bridge 2011). As a result, the spatialities and materialities of hydrocarbons, such as leapfrog development, vertical and horizontal choke-point geographies and the excessive leakage of carbon that has grave effects on the environment from the local to global scales, play a pivotal role in defining not only Arctic futures, but also the future of a Russia that is clinging to a hydrocarbon culture.

Second, from the perspective of politics of identity and culture, Russia's Arctic paradoxes do not seem as lapidary as the political economy of the Russian Arctic would entail. However, the way in which the governing regime constructs identities and promotes certain cultural forms does pose challenges for sustainable Arctic development. The manner in which Russian political discourse on the Arctic is constructed, and the way in which the Arctic is intertwined with nation-building efforts (Medvedev 2018), is very much related to how Russian territory and its resources in general have been operationalized by the regime as parts of national identity and culture. I refer here to the efforts by the governing regime and its central actors, such as Gazprom, Rosneft and Lukoil, to use the spatialities and materialities (infrastructures, flows and connectedness) of energy to construct a specific form of identity that views the nation's deep dependence on natural resources, especially fossil energy, as a strength that enhances Russia's role as a Great Power (see 
Chapter 3). Trying to sell this hydrocarbon culture and Energy Superpower identity to the Russian people (e.g. Bouzarovski and Bassin 2011; Rutland 2015) is thus fundamentally linked to selling the Arctic as a central geopolitical direction for the development of the Russian state and its sovereignty, as demonstrated by Laruelle (2012).

This identity coil amalgamating the Arctic and its resources is therefore also a pivotal factor influencing, if not determining, the way economies, cultures and the environment are treated at the level of policies and underlying politics. In order to understand why the question 'What comes after hydrocarbons?' has been seriously pondered in Russia - from Vladivostok to Moscow - so little, we must be aware of the cultural and identity dimensions of the issue. Among other things, constructed identities of hydrocarbon culture, coupled with meta-level processes in the sphere of political economy, explain why indigenous communities are kept in line and their livelihoods maintained through 'artificial respiration' taking place via subsidies provided by the hydrocarbon industries in compensation for pollution and loss of habitat. The practice of 'milking the oil men', which means distributing crumbs of wealth in the form of consumer goods and some social services instead of long-term strategic planning to enhance the Northern (indigenous) economies and cultures, has evolved because the regional and local administrations in the Russian Arctic are also part of a game that puts the hydrocarbon industry in the driver's seat and sets the direction (Henry et al. 2016).

Third, when examining the political ecology in the Russian Arctic, the problematic directions set by the political economy in Putin's Russia and the cultural and identity practices tied to it become even more evident. Russia's hydrocarbon industries pollute the air, waters and soil in the sub-Arctic and Arctic regions, first and foremost, to the detriment of Arctic ecosystems and the health of local populations. Since Russia's oil industry has been renationalized - following the privatization of Russia's oil industry in the 1990s, the state has acquired control of two-thirds of oil production - the state is to blame for the insufficient environmental policies in this field (Shapovalova 2017; Shvarts et al. 2016). An estimated 1-2 per cent of Russia's oil production, or 5-10 million tons of crude oil, is released into the environment during extraction and transport and 500000 tons of hydrocarbons enter the Arctic Ocean via rivers (Hese and Schmullius 2009). The yearly number of spills from failing oil pipelines ranges between 15000 and 20000 , but the exact number is unknown due to lack of transparency in the business and the state's lax attitude concerning environmental consequences (e.g. Vasilyeva 2014). Therefore, official figures concerning oil spills are not available and the 
numbers provided by energy companies are for the most part unreliable (Shvarts et al. 2016).

Moreover, approximately 15-20 billion cubic metres (bcm) of associated petroleum gas (APG), which is equivalent to 3 per cent of Russia's annual gas production and 10 per cent of the volume that EU countries import from Russia, is burnt in flares at Russia's oil production rigs. The increased level of APG utilization that has fortunately occurred since 2008 is the unintended result of the electricity sector reform carried out in Russia since 2008. Oil companies have been producing electricity from APG in mini-power plants and thus avoiding both capacity and retail electricity market payments, which has made them more energy efficient (Vasilyeva et al. 2015). However, even after this drastic reduction in APG flaring from over 50 to just $15-20 \mathrm{bcm}$, Russia is still by far the biggest polluter and accounts for from one-fifth to one-quarter of all APG flared globally even though it only accounts for 13 per cent of the world's oil production (Elvidge et al. 2018). Russia's APG flaring is exceptionally detrimental to the Arctic environment in two ways: gas flaring accounts for about 1 per cent of global energy-related GHG emissions (IEA 2018a) - meaning that 0.25 per cent comes from Russian flared APG - and the black carbon (BC), also known as soot, emitted during flaring accounts for half of all $\mathrm{BC}$ settling on and melting Arctic ice and snow. Recent research (see Shapovalova 2017; Stohl et al. 2013) suggests that $\mathrm{BC}$ is responsible for roughly one-third to one-half of all climate forcing in the region, thus contributing significantly to the double-pace warming the Arctic has experienced compared to lower latitudes. The root causes for the global Arctic paradox are global GHG emissions, to which all nations and economies contribute. However, the climate warming impacts of $\mathrm{BC}$ emissions from the Russian hydrocarbon industry account for a significant share of the overall climate impacts of Russia's emissions, and even a pivotal share of the warming in the Arctic. To put it bluntly, the Russian hydrocarbon industry, backed by the political economy of Putin's hydrocarbon culture, is speeding up warming of the Arctic and its subsequent exploitation. This is where a significant share of its future wealth is located, and it is as if the Russian hydrocarbon culture had turned into a 'geological force' transforming and forcing the Arctic natural ecosystem to serve the needs of the chosen culture. Oil and gas extraction is literally melting the ice to uncover yet another virgin deposit of Arctic oil and gas.

When the above-mentioned factors are taken into consideration, the way in which Arctic environmental change and global warming have been framed by the Russian elite for the general public comes as no surprise. There is consensus that Russia has not been at the forefront of 
global climate governance, but it has not openly tried to forestall international climate agreements either. Russia was part of the Kyoto Protocol and signed the 2015 Paris Agreement, although ratified it only in late 2019. However, the way that climate change in general, especially in relation to the Arctic, has been communicated by the state and its media tells a story of increased scepticism and outright denial of anthropogenic climate change and its negative impacts on Russia and especially its Arctic expanses (Palosaari and Tynkkynen 2015; Poberezhskaya 2015; see Chapter 6). I argue that a political economy tied to hydrocarbons and the identity construction needs of the governing regime concerning the Arctic and its energy resources leads to a regimefavouring and self-preservation narrative in which hydrocarbons and their societal effects are viewed in an exorbitantly positive light. In this narrative, the negative economic, social and environmental effects of deep socio-cultural dependence on hydrocarbons turns into a social taboo, as does climate change and its negative impacts on Russia and its Arctic expanses.

\section{RUSSIA'S DOMESTIC AND INTERNATIONAL POLICY STORIES ON THE ARCTIC}

Next, I will examine in greater detail how Putin's Russia has defined the Arctic to the domestic and foreign audiences. I argue that, as with the issues of energy as a geopolitical tool (see Chapter 4) and the causes of and need for action due to climate change (see Chapter 6), the story told about the Arctic is schizophrenic: the Russian people hear a message about how Russia the Fortress is threatened by forces from outside, whereas the narrative uttered by official Russia at foreign arenas and forums pictures Russia as an ideal law-abiding citizen of the global community aiming for mutual benefit via economic and political cooperation. Every country tries to define itself as a do-gooder on the international scene: all nations and states have a tendency to communicate in a different manner internally than with the outside world. However, the Russian double-speech (cf. Gessen 2017) is flagrantly beyond comparison among industrialized nations, and on par with highly authoritarian governments like China. I argue that this double-speech is a product of the hydrocarbon culture: in order to avoid jeopardizing its legitimacy, the Putin regime has no option other than to securitize environmental issues and exaggerate security threats to the Russian people. 
The analysis of domestic and foreign discourses is based on our (Gritsenko and Tynkkynen 2018) work concerning how the Arctic is defined in Rossiiskaya Gazeta (RG; domestic audience) and in official Ministry of Foreign Affairs (MoFA) communications between 2011 and 2015. On the surface, the key terms in internal and external communication alike reflect the agenda set by the official Arctic strategies of Russia: advancing international cooperation and harvesting the economic potential of energy and shipping. Moreover, both policy stories are in agreement about the basic assumptions that the Arctic has huge commercial potential for Russia; and Russia needs partners to unlock this commercial potential. However, while the point of departure on a meta-level is shared, the policy problems and solutions are defined quite differently. The internal story told by the state media includes a broad range of issues from socio-economic development and culture to security and the natural environment, whereas the MoFA narrative fed to foreign audiences focuses mainly on the international level and covers almost exclusively political and diplomatic issues.

Until 2014, the internal story was mainly concerned with unlocking the economic potential of the Arctic, but during and after that year the tone changed drastically: the Arctic was securitized to the Russian people. This included a claim that the Arctic may become a stepping-stone for other powers to influence and weaken Russia; and according to the Putin regime the remedy was to ensure a safer and more secure Arctic by building up Russian military capabilities in the region and beyond. At the same time as the domestic story became obsessed with territorial sovereignty and security, the story told on the international fora repeated the previous message, along with some nuances depicting the new security constellation between Russia and the West. Namely, the Arctic was now - more than ever - considered an exceptional area where conflicts elsewhere do not change the setting. This included reassurances that Russia is a 'good international citizen', and that Russia underlines the primacy of international law in the Arctic. At the same time, however, it was emphasized that economic sanctions set by the West are an obstacle to furthering bilateral cooperation. And here is the twist: the Arctic is pivotal for the continuation of hydrocarbon culture in Putin's Russia, and Russia is trying to build an image of itself as a law-abiding player while simultaneously trying to use Arctic resources - oil, gas and transport (from sea and aviation routes to telecommunication cables) - as leverage to get other powers to invest in Russia's Arctic hydrocarbonpropelled futures. This is in the hope that these economically attractive deals will persuade others to drop the sanctions against Russia. 
As our analysis shows, there are two clearly separated policy stories. We argue that the dualism in communication is first and foremost a sign that the Arctic is pivotal for the Russian government and the Putin regime. Each narrative not only serves a specific audience, but also presents us with a different set of policy problems and solutions relevant in a given setting. This finding further underlines the idea that there is not one, but at least two Arctics: one is a region within a sovereign state, the other is a region within a globalized world (Heininen 2018). The relationship between the two facets of Russian Arctic policy can be grasped by studying the relationship between the policy narratives.

Russia as a 'Great Arctic Power' is a powerful narrative for 'domestic use' that serves the goals of identity-building and justifies increased activity in the Arctic zone. Raising domestic awareness of the economic potential in the Arctic aims at strengthening political support among the domestic publics. Demonstrating how this potential can ensure the country's economic prosperity helps to justify public investment in expensive Arctic infrastructure projects. At the same time, this storyline has implications for international cooperation on Arctic-related issues. In order to meet the ambitious goals set by the Putin regime, the country needs to rely on cooperation with foreign partners to ensure access to the technology and capital needed for extensive Arctic exploration. Russia's image as a 'good citizen' in the world community who plays by the rules is a precondition for successful cooperation with other countries that will enable Russia to reap the benefits of the Arctic resource base, while sustaining the fossil fuel-based economy chosen by the regime (Gustafson 2012). This requires not only cooperative rhetoric in international fora, but a coherent set of international policy actions that strive to ensure multilateralism and regional cooperation in the Arctic. The policy stories built around the problems of Arctic industrial development and maintaining international stability support each other, particularly through cooperation.

We observe a different relationship between the two communication styles when it comes to the arguments that favour Arctic energy development. Russia's geopolitical leverage via energy, in other words, the energy superpower position (see Chapter 2), is an argument that supports Arctic energy development in the domestic story, while internationally energy trade is emphasized purely as a source of economic benefit. Again, the dualist communication strategy used in relation to the Arctic is not exceptional. For example, Russia's international discourse on climate change primarily pictures it as a serious threat, whereas domestically climate change is more and more defined via denial (Poberezhskaya 2015; see Chapter 6). Our study shows that in the case of Russia this 
contradiction between the two stories also exists regarding the Arctic. Moreover, the internal communication is more vulnerable to changes in the international political situation, as exemplified by the time frames before and after the Ukrainian crisis.

Finally, an interesting difference between the external and internal communication can be found in the sphere of the environment. While the domestic policy narrative is understandably broader than external communication, the fact that the natural environment is discussed three times more often in the RG newspaper than in the MoFA documents may appear counterintuitive, as the environment is usually considered an ideal candidate for international cooperation. On the one hand, this demonstrates that environmental issues are important for the Putin regime - at least rhetorically - when it discusses the Arctic and its exploration. This emphasis can be explained as a central legitimizing component in the otherwise economic-utilitarist discourse: by promising to clean up the environmental consequences of past Arctic exploitation and protect Arctic nature during the new rush, the regime is 'buying hearts' to support its Arctic nation-building effort. The relative lack of attention to international environmental cooperation in the Arctic in the MoFA documents can be attributed to the overall diplomatic orientation, which focuses on procedures (such as international cooperation via international organizations and bilateral instruments) and international law. In the absence of an Arctic environmental convention and the overall downplaying of climate change on the Russian Arctic policy agenda - climate change is treated as a source of opportunities and recognition of the local impacts of climate change is limited - relative ignorance regarding the environment in the external communication is understandable.

The environment, however, is used in the domestic story to legitimize the chosen policies of hydrocarbon culture: the environment is one of many tools used to move ahead with exploitation of Arctic hydrocarbons. The agenda of 'The Year of the Environment 2017' (Ministry of Natural Resources 2017) in Russia is telling: the Arctic environment is discussed only in terms of solving the problems of littering and pollution caused by economic and military activities of the Soviet state in the High North, as well as providing the energy companies and authorities with means to tackle future spills from the extraction of oil and gas in the Arctic. Importantly, none of the projects addressed climate mitigation. This indicates that environmental change that is visible for Russians, such as urban waste issues and local air pollution, also catches the attention of the regime, but the global environmental change that will cause much more severe effects for Russians and Russia does not. Environmental change in the Russian Arctic, partly caused by the actions of the 
hydrocarbon culture, remains in the realm of a taboo for the regime, whereas the environment is defined to serve the needs of the culture. Therefore, this story cannot include protecting the Arctic environment through climate mitigation, as that would challenge the rationality of the whole Arctic enterprise of Putin's Russia. Next, I will explain how the environment and sustainability are defined in the specific case of the Arctic gas business. This helps us to better understand the way in which the environment is operationalized for the cause of hydrocarbon culture.

\section{RUSSIA'S ARCTIC NATURAL GAS AND THE DEFINITION OF SUSTAINABILITY}

Sustainability as a corporate governance objective entered the Russian energy sector in the early 2000s. Major state-owned companies publish corporate social responsibility and sustainability reports. Instead of looking at these documents, I am interested in how sustainability is defined in advertisements directed towards the general public at home and abroad. I argue that the narrative found in these advertisements better reflects how the companies and audience that these commercials are intended for understand sustainability. Thus, advertisements are a productive site for analytically unmasking how Russian energy, political elites, and beliefs about commerce and responsibilities can be brought together.

When comparing how social and environmental sustainability is defined in two commercials produced by the Russian gas giant Gazprom, I see two distinct sustainabilities at play: an ethno-racist narrative intended for the domestic audience and a mainstream sustainability narrative targeting the international audience. Here, the same dualist take is visible as that unfolded above in the analysis of domestic media and government statements. My first example is a 30-minute documentarystyle video advertisement called Gazifikatsiya Rossii that tells the 'story of gas' (see Chapter 3), how it is produced in the Arctic periphery, transported through Russian lands and delivered to consumers in the Russian ethnic heartland. The narrative is appealing: gas is the substance that ties Russian space and ethnically Russian people together. Furthermore, amalgamating energy and people in this way promotes a Great Power identity based on natural resources and energy, an energy superpower identity that has been constructed during Putin's reign. The comparative ten-minute video is directed for the international audience and shows how Gazprom is committed to global social and environmental standards in its operations in Uzbekistan, Tajikistan and Vietnam 
(Gazprom International 2012). Here, the narrative abides by the scientific understanding of sustainability, and portrays Gazprom as an international company that is fully compatible with international social and environmental norms.

This brings up the question of whether Russian energy companies are trying to construct an image of a socially responsible player in an ethnically selective way in their domestic operations, while bypassing the environmental question that is central for the branch. I argue that Gazprom has tailored these commercials in a way that reflects what the audience anticipates, but also how the company and the political elite behind the company want to define their responsibilities. Thus, we see two distinct sustainabilities in Gazprom's videos: an ethno-racist narrative intended for the domestic audience that confines social responsibility to ethnic Russians and a mainstream sustainability narrative aiming at a balance between economic, social and environmental objectives while still pleasing the international audience. As I compare the narratives in these videos to the discussion on sustainability in Russia (Koch and Tynkkynen 2019; V.-P. Tynkkynen 2010), the lack of references to the need to reconcile social and environmental needs via democratic grassroots level empowerment is understandable. Thus, the challenge posed by environmental sustainability is viewed merely as a top-down management problem that is low on the political agenda. However, a new observation is that social sustainability is more central, but defined in a very narrow and ethnically discriminatory way. Moreover, the centrality of social responsibility in Russia's energy developments is, in my view, linked to both the official egalitarian discourse of the Soviet era as well as to the pressure experienced by hydrocarbon businesses as they operate in culturally fragile environments worldwide - from the indigenous lands of the Russian and Canadian Arctic to the Ecuadorian Amazon and the Nigerian Delta.

In light of the Arctic paradoxes facing Putin's Russia that were outlined above, we are very likely to see a balance between emphasizing 'hard' and 'soft' topics and approaches in Russia's Arctic policies: they are used in tandem for the benefit of the hydrocarbon culture, which is itself dependent on Arctic resources. However, as the High North is so central for Putin's Russia, there is a window of opportunity in the Arctic allowing the promotion of more socially and environmentally responsible policies and practices. Therefore, it is more likely that Russia will be more susceptible towards ambitious environmental policies within Arctic cooperation, as the Arctic needs to be kept 'exceptional' for the simple reason that the success of the Putin regime is tied to the fossil energy 
futures of that region. The problem in engaging with Putin's hydrocarbon culture in the Arctic is the difficulty of promoting practices that push Russia away from that culture and discouraging actions that are adding fuel to the fire for a regime that thrives on hydrocarbons. Thus, the practices and discourses of Russian hydrocarbon culture - the deeds and words of Putin's geo-governmentality (see Chapters 2 and 3) - maintain its power via the materialities and spatialities of energy, including the environmental dimension, in a very selective way. This environmental 'cherry-picking' needs to be confronted. The whole spectrum of the environmental effects of Russian energy, impacting first and foremost on the fragile Arctic, need to be unfolded and politicized (see concluding chapter), and turned into a tool that discourages investments in (Arctic) hydrocarbons and enhances a transition towards a carbon-neutral Russia. 